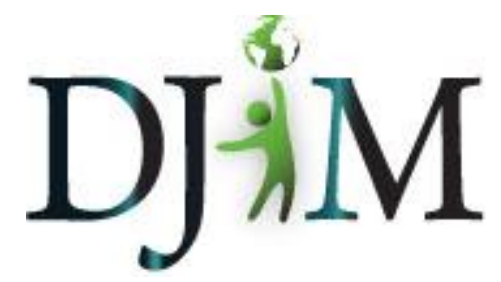

Volume 7 - Spring 2011 djim.management.dal.ca

\title{
Cinema during the First Two Decades of the Soviet Union: How Censorship of the Arts Inhibits the Dissemination of Information
}

\section{Lora Hamilton}

\begin{abstract}
This paper examines the increased censorship of film during the inaugural decades of the Soviet Union. Through an overview of the different genres and trends of Soviet cinema during this time, I draw parallels to the political climate and the role of film as an information medium. Censorship remains a persistent, if evolving, feature of the Communist Party's relationship with cinema throughout this time, and I conclude that in this case, censorship of art through the medium of film, is akin to inhibiting the dissemination of information.
\end{abstract}

\footnotetext{
About the Author(s): Lora Hamilton is currently enrolled in her first year of the Masters of Library and Information Sciences programme at Dalhousie, and holds a BMus (Hons) from Wilfrid Laurier University. She is interested in the role that arts, and their censorship, play in the dissemination of information, and hopes to become a music librarian. This paper was originally written for the MLIS course Information in Society.
} 


\section{Introduction}

Art is an integral part of human existence. It serves to develop a common bond between individual human experiences, society, the natural world, and the political world. It allows people to relate to their situation and to make sense of their surroundings. The Soviet Union was one example of a society where the social aspects of life were intrinsically linked with politics. In such societies, art as a means of allowing individuals and groups to disseminate their perceptions of the issues and realities they face, occupies a treacherous territory. By criticizing the Communist Party or offering dissenting views of the social situation, the artist is in turn criticizing the political powers that be. The artist finds himself in a difficult situation: one where the consequences of dissent, as seen in the Soviet Union, were often life-altering, if not life-ending. Film, as a relatively new development in the twentieth century, offered a whole new world of artistic opportunities. As well, it offered new opportunities for the political machine of the newly forming Soviet Union: the chance to spread information through propagandist efforts. Thus, cinema provided a means to communicate information, both in an artistic, subjective form and in an "objective manner."

By examining the role cinema played in the first two decades of the Soviet Union, it is possible to illustrate that increased control by the Party over this new medium corresponded to a type of censorship, censorship amounting to the repression of information due to an increasingly onesided representation and an inability for art to perform its function as a means of disseminating information. In order to illustrate this, the following ideas will be examined: cinema at the beginning of the Soviet Union; the role of the documentary, specifically leading up to the First Five Year Plan; the experimental period of fiction films leading up to the implementation of Socialist Realism; Socialist Realism and its effects on cinematic genre; and the parallels between political ideology, political stability, and cinema.

\section{Cinema at the Beginning of the Soviet Era Introduction}

As a relatively new medium in the early twentieth century, cinema was highly complementary to the ideology of the newly forming Soviet Union. First of all, because of its novelty, cinema was not weighted down by the cultural traditions of past society, as older forms of art were (Taylor, 1984). Theatre and literature, perhaps the closest relations to cinema, developed as part of the bourgeois tradition, which Marxist-Leninist ideology abhorred. Cinema, however, was a "genuinely popular cultural form," both because of its novelty and because it displayed exciting, new technology (Taylor, 1984, pp. 186-187). Moreover, early cinema offered great appeal to propagandist ends: it was purely visual and thus required no specific literary or linguistic capabilities of the audience (Taylor, 1984). Film reached beyond the realm of print in 
several ways: geographically, it was easy to transport across the vast territory; and the size of both its potential and real audience was far more significant than that of print material (Monas, 1984). Furthermore, the audience reaction to film, as compared to print, was less intellectual and cognitive, and more subliminal (Monas, 1984). All of these attributes meant that cinema was an excellent medium for disseminating messages to the masses; the latter attributes make a strong case for the inherent propagandist benefits of cinema.

Film played an important role during the inception of the Soviet Union. Because of its ability to reach mass audiences scattered across the vast territory, film was essential for spreading the message of the Revolution. In the beginning of the regime, films were considered an "education activity" and, as such, were placed under the responsibility of the People's Commissariat of Education1 (Levaco, 1984). This institution was created in 1917 and was headed by Anatoly Lunacharsky. In 1918, the chairman of Moscow Cinema Committee, Preobrazhenskii, stated the following: "Our duty before history is to film everything that we can and preserve it for future generations; our duty to the people is to show them everything that is happening now" (cited in Widdis, 2003, p. 13). This statement explains the Party's mentality; it was in the process of creating history and had an obligation to preserve evidence of its great achievements, both accomplished and yet to come. As well as an historical record, documentary film would be employed as an educational weapon to integrate the masses into the Party's construction of socialism (Widdis, 2003).

To serve this purpose of disseminating the Party's message, film had to be created and transported to the masses. Thus, the agit-poezd, or "propaganda train," was born. The agitka was a short film with an explicit propagandist purpose: to "educate the largely illiterate masses in the ostensible truth of the Bolshevik cause" (Gillespie, 2000, p. 4), and was born during the Civil war. Propaganda trains contained a printing plant, a theatre company, and a film crew, all of which enabled the convoys to capture desired footage. The first such convoy travelled to the front at Kazan in the summer of 1918, shot footage, and sent it back to Moscow (Widdis, 2003). The footage was then edited and processed by volunteers, after which it was sent across the territory and to other locations (Widdis, 2003) where it was used to incite popular support for the Bolshevik cause (Widdis, 2003; McLane \& Ellis, 2005). Propaganda trains continued to spread cinematic messages to the masses after the Civil War, and by 1925 there were 1,000 travelling cinemas with mobile projectors (Widdis, 2003). Agit-poezd showed Soviet films, most of which were documentaries and newsreels. By bringing national "news" to communities in such an accessible, novel format, the Party was able to control what information was disseminated to the masses. The newsreels presented sought to recruit peasants and workers to participate in the Party cause (Widdis, 2003; Spring, 1982).

In January 1925, Sovkino was created as a controlling body over cinematic production and distribution. Operations relating to cinema were centrifugal; the formation in July 1925 of the Society for Friends of Soviet Cinema (ODSK) grew from the need to create a "cinematic public" (Widdis, 2003, p. 14). ODSK created local organizations to support the "provision of cinematic 
equipment and involvement of cinema in the everyday life of the regions" (Widdis, 2003, p. 14). The Party obviously recognized that it was necessary to create a demand for the cinema within the masses; it was not sufficient simply to bring the cinema to the villages. The goal of ODSK was to establish a network between local and regional film committees; the cinematic public would then grow to depend on this network (Widdis, 2003). Thus, cinema in the Soviet Union was not yet centrally directed, but its role as a means of disseminating information was being recognized as crucial, and methods were being developed to further the Party's control over this medium.

\section{Role of the Documentary}

The documentary, as produced in the Soviet Union during its first two decades, performed a key ideological task: it strove to educate the masses, many of whom would be otherwise isolated and unaware of the progress that was occurring. The First Party Conference on Cinema, which was held in March 1928, clearly stated that film must be a weapon in social transformation and the creation of a unified Soviet people (Widdis, 2003). The First Five-Year Plan (1928-1932), which was designed to mobilize the Soviet Union in order to match the progress of capitalist nations, "necessitated an intensified programme of "cinefication"' (Widdis, 2003, p. 15). As a result, the number of travelling cinemas almost doubled during 1928 (Widdis, 2003). Newsreels distributed during this time included Film Week and Kinopravda (Film-Truth); the latter bears the same irony as the title of the news publication Pravda (Truth): the term "truth" could be applied with the caveat that it was the Party's "official truth"; the one it wanted to share with the public.

The genre of "documentary film journals," which are documentary films produced as a series, also increased during the First Five-Year Plan. Titles such as Union Film Journal, coordinated by the Union of Film Chronicles, released 39 editions in 1926 growing to 84 silent films in 1929; subsequently, it never produced fewer than 70 films a year (Widdis, 2003). Other documentary film journals included: For a Socialist Village, which encouraged local activists in pursuit of collectivization and the integration of peasants; and Our Achievements, which accompanied a printed journal edited by Maxim Gorky and aimed to involve the periphery in the actions and achievements of the centre (Widdis, 2003). These films were composed of fragments taken from different regions; this fragmentary method served to emphasize the contributions of the regions to the achievements of the state (Widdis, 2003). Again, the Party was using its ability to control the dissemination of information through film to share an approved version of events; these films were aimed at encouraging participation by proving the success of the Revolution and the new system as it was developing.

The documentary was a particularly critical genre for the purposes of centralized planning, which occurred both under the New Economic Policy (NEP) and the First Five-Year Plan. For instance, the electrification plan undertaken by Lenin was prominently featured in documentary films. The cinema's purpose was to spread the news of such a useful endeavour and to 
encourage participation. Electrification would be a practical undertaking and would prove very useful. As well, the documentary footage created the impression of "Soviet historic present" (Widdis, 2003), which refers to current developments that were "making history. The First FiveYear Plan, as mentioned earlier, was an enormous plan to catch the Soviet Union up to rival capitalist nations, to prove its worth as an ideology for the "historic present." In order to inform the masses of the events unfolding within the territory, a massive propaganda campaign was undertaken, a main component of which was cinematic. Films were created, sometimes within hours of a project being completed. These films gave the opportunity for the masses to experience these great developments from all across the state as if they were actually present. As a genre, documentaries produced in the first two decades of the Soviet Union were highly propagandist: they focused on the positive achievements (both real and, as time went on, increasingly fictional) of the state and aimed to include the whole nation in the glory of these monumental achievements.

One example of a particularly false depiction of events in the Soviet Union featured collectivization, which occurred in 1929. The propaganda depicted collectivization as a "rationally ordered transformation" from the traditional peasant communes to the new Soviet order (Widdis, 2003, p. 39). However, in reality collectivization was not centralized; rather, it was chaotic and the ensuing "assault on the countryside was at best disorganized, and often violent and coercive," as multiple levels of authority attempted to fulfil the wishes of the Party (Widdis, 2003, p. 39). The fact that this disparity existed between the documentary portrayal and reality indicates that the Party was unable to control the periphery. However, by controlling the propaganda - cinematic images presented to the masses - the Party could control the message presented to the masses. The creation and dissemination of highly propagandist images provided a one-sided depiction of the situation. While the footage of a documentary may be taken from a real event, when its context is altered, it can create false perceptions. Thus, the documentaries produced by the Party during its first two decades were censored in order to achieve Party ends and were communicated in a one-sided, misleading fashion.

\section{Experimental Period of Fiction Films leading up to Socialist Realism}

The period from 1922 until the implementation of Socialist Realism in 1932 is often referred to as the "Golden Age" of Soviet cinema. This was a period before the Great Purge of the 1930s; artists were encouraged to experiment with film while receiving support from the Party. As well, the New Economic Plan (NEP) was in place during much of this time, and was applied to film. NEP, which lasted from 1921-1928, was a "compromise, a temporary retreat on the road to socialism" which would allow the country to recover from the devastating effects of the Civil War and the resulting War Communism (Riasanovsky \& Steinberg, 2005, p. 476). Essentially, NEP was a mix of socialism and private enterprise, a combination that proved to be quite successful economically; despite the considerable political tension it created (Riasanovksy \& 
Steinberg, 2005; Kenez, 1988). The film industry was highly conducive to NEP (Taylor, 1984); as the Soviet Union lacked the ability to domestically produce enough films to satisfy demand, making the importation of foreign film an ideal solution (Levaco, 1984). The Party encouraged the formation of "trusts" in the film industry, which were "state regulated administrative organs controlling ... enterprises and operating on a profit basis" (Levaco, 1984, p. 176). Until 1928, imported films were more commercially successful than domestically produced cinema (Taylor, 1984). However, the film industry became the subject of intense debate during the mid- to late1920s: the question as to whether it was more important to have films that were "intelligible to the millions," to use Lunacharsky's phrase, or to continue with the current atmosphere of "provocative experimentation" (Levaco, 1984, p. 176) was continuously raised.

During the 1920s, state censorship organs were burgeoning. In June 1922, Glavlit (Main Administration for the Safeguarding of Military and State Secrets in the Press) was charged with overseeing the censorship of all information, both printed and pictorial, in the Soviet Union. This meant that the film industry was centralized under Glavlit, and further centralized under the Commissariat of Education (Levaco, 1984). The entire cinematic process was saturated with censorship: preproduction, including the writing and the budget; production, or the actual shooting; and post-production, involving the editing, printing, and release, were all subject to approval by the censor. As well, the censor retained control of distribution, screening, the number of prints produced, the charges for rental, and the conditions of foreign release (Levaco, 1984).

Despite this seemingly rigid and ubiquitous involvement of censorship in cinema, Soviet film during the 1920s flourished. This is owed, perhaps, to the fact that cinema was still a relatively new medium, and one that related closely to the world of dreams, which, according to Monas (1984), constitute an elusion of the censor. The subjectivity and complexity of film made censorship a difficult task, and some may take the view that censorship, in fact, encourages and drives the artist to find new, subversive, creative ways to elude capture and censorship of his work (Monas, 1984). However, prominent directors of Soviet film during this decade were largely interested in furthering the message of the Revolution and depicting this new world through a new art (Gillespie, 2000; Taylor, 1984). The following two quotations illustrate this idea:

Most directors saw film not as an entertainment medium, but primarily as a specific means of channelling ideas and images to the viewer: an instrument of propaganda. (Gillespie, 2000, p. 6)

[Major Soviet directors of the 1920s] sought to restructure the way people both saw and thought about social phenomena, to radicalize and reorganize the very process of perception and cognition through film and its stylistic repetition.

(Levaco, 1984, p. 178) 
The "propaganda" Gillespie refers to does not necessarily indicate State-propaganda per se; it could also refer to the desire of Soviet directors to spread belief in the Revolution and the Bolshevik cause in which they so strongly believed. Both of these quotations do, however, speak of the need for art, in this case, film, to act as a means of disseminating cultural information. Through the use of this exciting, new medium, artists (directors) were able to express new truths, albeit subjective ones, about their surroundings and disseminate their views to an audience. This expression of views is a critical function of art as a disseminator of information in the form of subjective truth; censorship of this function results in inhibited dissemination of information.

As mentioned earlier, a heated debate began during the mid-1920s concerning whether cinema should be conducive to mass audiences or continue in its current, experimental, and as officials were inclined to believe, elitist form. The 1928 Party Conference indicated concern that films were either too commercial and imitative of Hollywood (bourgeois) ideology, or were too avant-garde and experimental, thus making their message "unintelligible to the millions" (Taylor, 1984). Lunacharsky, who was still in charge of the cinematic industry at the time, called for films to be both ideologically and popularly acceptable (Taylor, 1984). The metaphorical noose tightened even further on cinematic artistic expression in January 1929, when a decree was issued calling for the Party to strengthen its leadership over cinema in order to prevent it from becoming part of the "non-proletarian strata": "Party, professional, Komosol, social, and scientific organizations should play a more active part in the work of the cinema" (Taylor, 1984, p. 191). Thus began what Taylor (1984) terms the "proletarian episode in Soviet cinema" (p. 192), which concluded with the end of the First Five-Year Plan. This "proletarian episode" was undertaken in order to enact the "cultural revolution" that was called for by the First Five-Year Plan (Taylor, 1984). Lunacharsky resigned in 1929, and in early 1930, Soviet film was centralized into Soiuzkino, at whose head was Boris Shumyatsky. His main goal was to create a Cinema for the Millions, which is the title of a book he published. From the time that Shumyatsky became the head of the cinematic industry in 1930, the Party continued to tighten its control and increase censorship.

\section{Socialist Realism and its Effects on Cinematic Genre}

The implementation of Socialist Realism was initiated in 1932 when all literary and artistic groupings were abolished. Riasanovsky and Steinberg (2005) define Socialist Realism as:

the truthful, historically concrete depiction of reality in its revolutionary development [where] the truthfulness and historical concreteness of the artistic depiction of reality must be combined with the task of ideologically remolding and educating the working people in the spirit of socialism (p. 576).

Artists, including those involved in literary fields, film, and music, were essentially employees of the state and their art was an organ of the government; therefore, Stalin and his associates 
were able to dictate the acceptable content for the arts (Riasanovksy \& Steinberg, 2005). There were two main causes for concern involving cinema: the advent of sound and the goal of making films that were both popular and ideologically "correct."

The advent of sound in film was met, at best, with concern, but often with nothing short of terror (Taylor, 1984). This can be attributed to natural human adversity to change, but also to more practical causes. Adding sound to film, and thus dialogue, created greater similarities to the genres of literature and theatre, both of which were laden with the "baggage" of bourgeois tradition. The main distinction, within the Soviet Union, of cinema as a new art, and thus appropriate to the Revolution and its causes, was its silence and the technique of montage (Taylor, 1984). As Yevgeny Gabrilovich stated:

People at the time maintained the silent montage was more intelligent, more complex, more grandiose, more infinite, and more philosophical than words... [Dialogue] was perceived as the symbol, the sign, the spectre of the literature that was so rejected (cited in Taylor, 1984, p. 194).

Thus, because film was perceived as threatened by the "spectre" of bourgeois tradition, it stands to reason that increased censorship was required in order to protect the ideology of the Soviet Union in film.

The problem of genre and of creating popular films was also of great concern to the political powers in place during the 1930s. During the so-called "Golden Age" of Soviet cinema in the 1920s, experimentation was prevalent; these films were viewed as elitist because they were only intelligible to the few (Kenez, 1988). The other films produced during the silent era were problematic because they mirrored too closely the Hollywood model, thus they were imbued with bourgeois ideology (Taylor, 1984). These problems, combined with the perceived threat of sound in film, provoked the Soviet Union to create its own, distinct genres, which would be "intelligible to the millions": they would be ideologically aligned with the Party and would also be popular. The genres created under Socialist Realism were not to include documentary, only fiction (Taylor, 1984). There is obvious irony in this decision: the term "realism" was not a descriptor for the actuality of the situation in the Soviet Union, but rather for what the Party desired the reality to be.

According to Taylor (1984), two distinct sub-genres of fiction were created during the period of Socialist Realism: the "historical-revolutionary film" and the "socialist reconstruction film" (pp. 198-199). Both of these genres served to support the ideology of the Party, to glorify the accomplishments of the regime, and to create sustained optimism for the continuing work of the Revolution, all the while providing Soviet cinema-goers with entertainment. The historicalrevolutionary film's main role was to legitimate the Revolution and the Soviet order it established (Taylor, 1984). The other uniquely Soviet genre, the socialist reconstruction film, sought to develop and update the themes of historical revolution-type films and to confront 
more contemporary problems (Taylor, 1984). It is important to bear in mind that, in such a highly politicized society as the Soviet Union, criticism of social problems was also criticism of the regime. Therefore, to comply with Socialist Realism, films had to have an optimistic and inspirational conclusion: film was not reality; it was depicting reality as it would be, or, more accurately, as the Party wished it to be. This sentiment was obvious at the time: Lunacharsky himself stated that the Socialist Realist "does not accept reality as it really is. He accepts it as it will be" (cited in Taylor, 1984, p. 202). When exactly this reality was to manifest itself was unclear.

What was clear was the fact that questioning the validity of the Soviet regime or of the Revolution was unacceptable. The Party was threatened by cultural pluralism, and felt this pluralism needed to be extinguished (Kenez, 1988). During the period of Socialist Realism, film was ever increasingly inhibited from acting as an art form that could help both artists (directors) and audiences come to terms with their reality. By forcing the cinema to portray highly fictional, purely idealistic situations, the Soviet regime was stifling the role of art as a means of interpreting complex human realities. All films were required to have a positive, happy outcome, which led to a lack of films dealing with contemporary issues (Taylor, 1998). Stifling art is akin to stifling a useful and necessary means of disseminating complex and diverse points of view. If one takes the expressionist perspective of art as portraying an inner reality, a reality inexpressible through imitation of outward reality ("Expressionism," 2008), art provides a perspective that is equally important, and perhaps more crucial, than that provided by "objective" information. By implementing Socialist Realism, the Soviet Union was not allowing directors to express actual reality or to treat contemporary social issues, much less to express an "inner reality." An imposed, artificial, creativity-stifling artistic situation is a definite form of censorship. This creates an imposition on the freedom of information, be it disseminated through cultural, artistic means, as is the case with film, or through more traditional and perhaps more respected objective forums.

\section{Parallels between Political Ideology, Political Stability, and Cinema}

Censorship was, from its inception, an integral part of the Soviet Union. In this specific case, censorship is not simply an unavoidable and inherent part of any totalitarian regime. Rather, Marxist-Leninist ideology considers censorship to be a necessary state function. MarxistLeninism considers analysis of human history, rights, and revolution as inherently ideological and class-based, as opposed to a "Western" belief that individuals begin life in a blank or neutral state (Levaco, 1984). Therefore, in the Soviet Union, censorship was viewed by the Party as a responsibility of the state: it had to countervail and countermand the class-based "natural" attitudes, ideas, and dispositions entrenched inherently in people's minds (Levaco, 1984). This was, of course, a convenient clause of Marxist-Leninist ideology, as it allowed the

state to control the information disseminated amongst the masses. As well, censorship was 
necessary in order to secure change: the Revolution was under constant threat, especially in the beginning. During the period of War Communism (1917-1921; following which NEP was introduced to help the State recover from the deleterious effects of War Communism), the Bolsheviks were fighting the White Army on three fronts, in addition to intervention by Japan, the United States, and several European powers (Levaco, 1984). Therefore, a kind of "crisis mentality" developed, which led to an increased need to censor "counter-revolutionary" material (Levaco, 1984).

The fact that Marxist-Leninist ideology accounted for state censorship as an inherent responsibility is both convenient and clever. A distinct parallel exists between the censorship employed by the state and Stalin's political struggles and rise to power. Film directors of the early Soviet Union were keen to use this new art to promote the message of the Revolution and the Party and to disseminate this message to the masses. As was previously mentioned, the immediate and direct nature of the perceived threats to the Revolution during War Communism caused the Party's most pressing concern to be the elimination of "counterrevolutionary" material. Even after the end of War Communism and the commencement of the New Economic Plan, the Party tolerated and sometimes encouraged experimentation and innovation in the arts, including film. This experimentation was, of course, under the caveat that the material produced was not deemed "counter-revolutionary." However, during the course of the 1920 s as the debate over film "intelligible to the millions" developed, the "Party line" of what material was acceptable was in transition and the "tolerance that was extended to various groups in the 1920s was giving way to the cultural straightjacket of the 1930s" (Taylor, 1998 , p. 43). The goal of censorship during the 1930s was to remove ambiguity in meaning; to achieve "one-meaningness" (odnoznachnost') (Plamper, 2001). While film during the "Golden Age" was heavily involved in promoting the Soviet doctrine, it still managed to be an expressive art form. At this time censors forced artists to become creative in their ways of expressing a subversive message; films were touted as a highly subliminal medium, after all.

The Party machine was occupied with in-fighting throughout much of the 1920s. Stalin became the Secretary of the Communist Party in 1924 upon Lenin's death. However, he still had to contend with his most significant rival: Trotsky. Stalin defeated Trotsky in 1927, and exiled him the following year. The First Five-Year Plan was introduced around this time, and 1929 marked Stalin's defeat of the right opposition. Thus, Stalin managed to secure the leadership of the Communist Party and the Soviet Union. Throughout this time, censorship was becoming increasingly centralized and restrictive, until it came to a head in the artistic realm with the implementation of the ambiguous yet incredibly restrictive policy of Socialist Realism. It is interesting to note that "from the mid-1930s Soviet films [were] increasingly occupied with leader figures, all of whom explicitly or implicitly represent Stalin" (Taylor, 1998, p. 56). Following Lenin's death, the rise of his personality cult helped Stalin secure his place as Secretary of the Communist Party. This was charted in films, which transitioned from Lenin as the hero, to Lenin with Stalin as his "right hand man," to Stalin taking up Lenin's mantle, to 
Lenin disappearing as part of Stalin's myth, therefore leaving Stalin standing alone (Taylor, 1998). This fascinating transition parallels Stalin's rise to complete control over the Soviet Union, and also reflects the total control he had over the dissemination of information, which translates as an artistic, cultural forum in film.

Part of the First Five-Year Plan was a "cultural revolution", which revolution involved an extensive element of cinematic propaganda. The cultural revolution included increasing involvement of the state in film production and the creation of more state organizations in charge of controlling all aspects of information, including cultural forums. Censorship of this era has been described as "total, ambient, banal control" (Levaco, 1984, p. 176). The First FiveYear Plan also marked the shift from practical, pragmatic planning to conceptual planning; it "was the victory of "teleological" (target-oriented) planning over "genealogical" (pragmatic) planning"; the triumph of "imposing dreams on reality" (Widdis, 2003, p. 31). By censoring cultural output, as well as other forms of information, "it was the Party that was to determine the portrayal of future reality, even if it could not determine that future reality itself" (Taylor, 1984, p. 202). Films became shallow, artificial shells that reflected the idealistic dreams instead of the reality of the Soviet existence.

\section{Conclusion}

During the first two decades of the Soviet Union, cinema represented a new medium, one that was not laden with the "baggage" of bourgeois tradition. Film was immediately recognized by the Bolsheviks as an essential tool for disseminating their message to the masses that occupied a vast and disconnected territory. Cinema, in the form of documentary film, was transported across the country to incite popular support for the Revolution and the Bolshevik cause. Cinema also enjoyed a "Golden Age" in the Soviet 1920s, where highly experimental films were created as directors attempted to further disseminate the Revolution's message through cultural means. However, as the need for increasingly centralized censorship and the desire to create cinema "intelligible to the millions" developed, and coincided with Stalin's securing of the position of Secretary, cinema became a vacuous, propagandist form of entertainment pushed forward by Socialist Realism, an ideology that supported the conceptual and unrealized ideals of the Party. Cinema was used throughout the first two decades of the Soviet era for propagandist purposes. Propaganda often marches hand in hand with censorship, which, in the case of the Soviet Union, was the responsibility of the state, as indicated by Marxist-Leninist ideology. Censorship by itself is a violation of information's ability to be disseminated. When coupled with propaganda, censorship creates a one-sided representation of a situation; the information available does not create a complete picture, nor is it inclined to be neutral. By denying a society the opportunity to create a multi-dimensional portrayal of its existence through art, Socialist Realism, censorship, and propaganda were inhibiting the dissemination of information through the arts.

\section{Notes}


1. Names of State organs are referred to in the English translation, except for short forms and acronyms. 


\section{References}

Expressionism. (2008). In The Columbia Encyclopedia. Retrieved from http://www.credoreference.com/entry/columency/expressionism

Gillespie, D. (2000). Early Soviet cinema: Innovation, ideology and propaganda. London: Wallflower Publishing Ltd.

Kenez, P. (1988). The cultural revolution in cinema. Slavic Review: Interdisciplinary Quarterly of Russian, Eurasian, \& East European Studies 47(2), 414-433.

Levaco, R. (1984). Censorship, ideology, and style in Soviet cinema. Studies in Comparative Communism 17(3/4), 173-183.

McLane, B.A., \& Ellis, J.C. (2005). New history of documentary film. London: Continuum International Publishing Group Ltd.

Monas, S. (1984). Censorship, film, and Soviet society: Some reflections of a Russia-watcher. Studies in Comparative Communism 17(3/4), 163-172.

Plamper, J. (2001). Abolishing ambiguity: Soviet censorship practices in the 1930s. Russian Review 60(4), 526-544.

Riasanovsky, N.V., \& Steinberg, M. D. (2005). A history of Russia (7th ed.). New York: Oxford University Press.

Spring, D.W. (1982). Soviet Newsreel and the Great Patriotic War. In N. Pronay \& D.W. Spring (Eds.), Propaganda, Politics, and Film, 1918-1945 (pp. 270-292). Hong Kong: MacMillan Press Ltd.

Taylor, R. (1984). Soviet socialist realism and the cinema of the avant-garde. Studies in Comparative Communism 17(3/4), 185-202.

Taylor, R. (1998). Film propaganda: Soviet Russia and Nazi Germany (2nd ed.). New York: St. Martin's Press.

Widdis, E. (2003). Visions of a new land: Soviet film from the Revolution to the Second World War. New Haven: Yale University Press. 